\title{
El engranaje de las máquinas: ¡Un arquito más! Reconstruir y rememorar la historia, promueve a reivindicar la identidad de un pueblo minero que lucha por su sobrevivencia
}

Gisel Elvira Barboza *

\section{Resumen}

El presente proyecto tiene el objetivo de generar acciones socio-educativas mediadas por la tecnología en la cuenca carbonífera para conocer las trayectorias laborales y clivajes culturales que tienen los mineros jubilados del Yacimiento Carbonífero Río Turbio (YCRT) recuperando sus propias voces. En ese punto, se comprende el relato oral del minero y su familia como un elemento significativo para la construcción de la historia del Yacimiento carbonífero, particularmente los mineros que participaron en las luchas laborales que se suscitaron en la década de 1990 por la defensa y continuidad de la fuente productiva, la cual es generadora de existencia de los pueblos identificados por la extracción minera.

Recuperar la memoria colectiva por parte de los protagonistas y poder colocarla en valor, implica registrar esferas transversales como la identidad, la familia, la trayectoria laboral, el espacio compartido entre pares y otros clivajes culturales. Los cuales, son polos de identidad que van conformando subjetividades, que unidas, forman parte de estándares que el minero y su grupo exalta y replica con grandeza. En ello, destacamos que estos mineros que referenciamos, tuvieron su ingreso en la mina en tiempos finales del peronismo en Argentina, momento donde aún se enmarcaba fuertemente la ideología de cultura del trabajo.

Por último, destacamos que los mineros que se jubilaron posterior al año 2004 son nuestra población objeto, los cuales, por un lado vivieron eventos trascendentales en cuanto a la conquista de derechos laborales a partir de luchas por la continuidad de la fuente laboral, tal como la del año 1994, y por otro, esta franja etaria también evidenció el siniestro del 14 de junio del 2004, instancia trágica que conllevó a mayores políticas en seguridad laboral y el inicio de contratación de personal joven, los que se caracterizaron en su mayoría por ser hijos y familiares de mineros.

Palabras clave: $\quad$ Cuestión minera - Trayectoria laboral - Siniestro - Memoria colectiva 


\title{
The gear of the machines: One more arc! Reconstructing and recalling history, promotes to vindicate the identity of a mining town that fights for its survival
}

\author{
Gisel Elvira Barboza *
}

\begin{abstract}
The present project has the objective of generating socio-educational actions mediated by technology in the coal basin to learn about the labor trajectories and cultural cleavages that retired miners have from the Río Turbio Carboniferous Deposit (YCRT), recovering their own voices. At that point, the oral account of the miner and his family is understood as a significant element in the construction of the history of the Coal Field, particularly the miners who participated in the labor struggles that arose in the 1990s for defense and continuity. of the productive source, which is the generator of existence of the peoples identified by mining extraction.

Recovering the collective memory by the protagonists and being able to place it in value, implies registering transversal spheres such as identity, family, work trajectory, shared space between peers and other cultural cleavages. Which are poles of identity that are shaping subjectivities, which together, are part of standards that the miner and his group exalt and replicate with greatness. In this, we highlight that these miners that we referenced, had their entry into the mine in the final days of Peronism in Argentina, a time where the ideology of work culture was still strongly framed.

Finally, we highlight that the miners who retired after 2004 are our target population, which, on the one hand, experienced momentous events in terms of the conquest of labor rights from struggles for the continuity of the labor source, such as that of 1994, and on the other hand, this age group also evidenced the accident of June 14, 2004, a tragic instance that led to greater policies on occupational safety and the start of hiring young personnel, which were characterized mostly by be children and relatives of miners.
\end{abstract}

Keywords: $\quad$ Mining issue - Labor history - Claim - Collective memory 


\section{Problema y/o situación a resolver}

El Proyecto propone el abordaje en la población de la tercera edad desde un marco extensivo y de investigación-acción. Creemos que para la construcción histórica del Yacimiento Carbonífero Rio Turbio se deben generar espacios culturales de trasmisión para que los jubilados mineros nos relaten sus experiencias, historias de vida, nos narren su llegada a la cuenca, las luchas por la continuidad de la fuente laboral, y, lo que significo en muchos de ellos y su familia la pertenencia en este reciento laboral caracterizado por diversos estudios como peligroso para el ser humano.

Para la concreción del objetivo "generar acciones socio-educativas mediadas por la tecnología en la cuenca carbonífera para el reconocimiento y preservación del relato oral de las trayectorias laborales y clivajes culturales que tienen los mineros jubilados del Yacimiento Carbonífero Río Turbio (YCRT)", proyectamos que por medio de espacios socio educativos mediado por la tecnología se rescaten relatos de vida, trayectos laborales en la mina, luchas trascendentales en defensa de la continuidad de la empresa y las representaciones sociales del minero por parte de las familias de la cuenca carbonífera.

Entonces, a partir de actividades reflexivas, los moderadores efectuaran un ejercicio de abstracción a partir de la práctica concreta. Desde la perspectiva crítica (Freire) sostenemos que la acción de educar y aprehender consiste en escuchar desde un margen de auto criticidad y reflexión acerca de nuestra historia, reflexionando acerca del lugar que ocupamos en el mundo, y el porqué de los procesos sociales a partir del conocimiento sobre la estructura económica.

Por último, para vivenciar la historia pasada, se debe romper con las naturalizaciones, considero que en esta era de modismos, individualidad y consumismo por parte de un modelo económico perverso que pretende el rompimiento de los lazos sociales y la escucha entre unos y otros, hemos de enfocarnos en la construcción de sujetos críticos que reivindiquen desde un aspecto de derechos sociales y culturales, a la valorización de la memoria colectiva, la inclusión, la solidaridad, la libertad y la ciudadanía.

\section{Contexto social y cultural}

Entendemos desde el Proyecto, que la población de la tercera edad es pedestal de la sociedad y narrador principal en la historia de la Cuenca. Sin embargo, podemos dar cuenta por medio de desarrollos teóricos, que los cambios socio culturales e ideológicos en las relaciones sociales acaecidos por la globalización instaurado a posterior del modelo benefactor, ha desconfigurado y quebrado las instituciones constructoras de sentido en el sujeto, tales como la familia y el trabajo.

Concebimos que estos fenómenos sociales, producto del modelo Neoliberal hoy llamado Neo-desarrollista, apuntalan a estructurar lo social con determinados parámetros muy contrarios a la escucha, a la unidad, a la coherencia social, a la justicia, a la equidad y a la inclusión. Además, se colocan en evidencia múltiples factores socio-institucionales por 
parte de estas entidades rígidas, que instalan una falsa culpabilidad en los sujetos, no permitiendo ver el trasfondo socioeconómico que es causante de las problemáticas.

Entendiendo, que los problemas y/o situaciones que acaecen en el sujeto no pueden ser analizados sin la relación con el contexto. Identificamos que se torna indispensable que tanto las instituciones locales y los actores sociales problematicemos los mecanismos explícitos e implícitos que el modelo económico actual desprenden en lo social acerca de la tercera edad. Porque si seguimos vedando la exclusión como problema social, nos seguimos automatizando a los parámetros legitimados por un modelo económico que individualiza y separa. Lo que indubitablemente nos hace individualistas, y mecánicamente no nos permite reflexionar y resignificar la memoria colectiva de los pueblos carboníferos.

Si nos remontamos al tiempo de los años 90, según Graciela Labarthe (2014) el carbón del Rio Turbio era extremadamente demandado por ser un material energético, sin embargo, durante esa década, se empezó a denotar un Estado que comenzó a ser deslegitimizado por el mercado en virtud a las medidas económicas de ajuste estructural. El gobierno menemista a partir de la privatización produjo una alta cantidad de despidos y retiros voluntarios en el YCF. Si bien los gremios ya funcionaban, fue desde 1994 donde se dejó entrever la identidad laboral, el sentido de pertenencia, la unión y la lucha por la continuidad de la empresa y garantización de derechos.

Entonces, desde un aspecto socio-económico, la privatización de la empresa YCF no procuró un futuro de bienestar en el minero, por el contrario, aparecieron nuevos conflictos en la producción entre compañeros, decadencia en cuanto a la precarización de materiales y desvalorización del minero, ya que el salario era totalmente bajo. La organización sindical y las luchas laborales de mineros y sus familias se empezaron a hacer oír a nivel nacional, no siendo solo la empresa YCF la que exigía, sino también todo un país que se concentraba en el malestar social.

Por estudios últimos que he realizado en términos de investigación, en los años posteriores al 2000, los mineros de la cuenca carbonífera obtuvieron una parte de las respuestas a las varias luchas generalizadas por todos los pueblerinos, es decir, la empresa YCF vuelve a ser intervenida por el Estado Nacional Argentino. Sin embargo, el siniestro fatal ocurrido en interior de mina el 14 de junio del año 2004 que se llevó la vida de 14 mineros y la llegada de Néstor Kirchner como presidente de la Nación, fue lo que produjo en términos de reivindicación de derechos laborales, una ruptura y cambio de vida más digna en los mineros y su familia.

Hoy en día, la mina de carbón sigue siendo actualmente la fuente de trabajo de varias localidades aledañas, comunidades que siguen desarrollándose tanto urbana, demográfica e institucionalmente ya que se sigue contratando masivamente mano de obra. Esto se debe a que en la cuenca carbonífera se construyó la Usina Termoeléctrica que tiene por objeto trabajar en conjunto y sumarse al interconectado energético del país. 


\section{Objetivos}

\section{Objetivo general}

Generar acciones socio-educativas mediadas por la tecnología en la cuenca carbonífera para el reconocimiento y preservación del relato oral de las trayectorias laborales y clivajes culturales que tienen los mineros jubilados del Yacimiento Carbonífero Río Turbio (YCRT).

\section{Objetivos específicos}

- $\quad$ Promover actividades sociales de índole literario y artístico que permitan identificar las representaciones sociales que tienen las familias y los pueblerinos de la cuenca acerca del minero del YCRT.

- Indagar en las trayectorias laborales y eventos trascendentales que acontecieron los mineros hoy jubilados de la mina de Rio Turbio.

- $\quad$ Recopilar y confeccionar artículos académicos y literarios que vivifiquen la historia de los mineros a los fines de conservar la memoria colectiva.

- $\quad$ Fortalecer la vinculación institucional de la UART con las asociaciones civiles y sectores populares.

\section{Justificación y relevancia}

El proyecto busca generar la importancia en acciones de gestión del patrimonio cultural del Yacimiento Carbonífero de Rio Turbio con el fin de conservar la memoria y preservar los elementos significativos. Por ello, destacamos que la creación de espacios socio educativos de escucha y reflexión de las trayectorias del minero en este caso mediados por la tecnología, constituirán parte importante de recuperación de la historia propia de los pueblos que se caracterizan por la extracción minera.

En ese sentido, se prioriza la historia de los mineros antiguos, el sentido de pertenencia de los habitantes del lugar, las vivencias de las familias, hábitos y actos culturales de la zona, los primeros barrios instalados y los edificios que se construyeron desde los inicios de la explotación del carbón, y eventos que resignifican el valor por la minera como fuente laboral de la cuenca. En ese caso, tomaremos como eje central de recolección y recuperación a las luchas generadas en defensa de la mina suscitada en el tiempo menemista, más precisamente en el paro generalizado de la cuenca en el año 1994 por el pedido del no cierre de la empresa, con el fin de profundizar en la memoria del lugar y los elementos significativos que acuna la zona minera.

A los fines de promover la revalorización de la historia minera y los elementos significativos del Yacimiento carbonífero, se proponen rescatar los relatos de la trayectoria laboral de los mineros en pos de resignificarla. Consideramos que estos son aportes que 
contribuyen a la concretización de acciones futuras de gestión del patrimonio cultural de forma integral y con el compromiso y la participación de los diferentes actores. Así mismo, se constituye como fortaleza de esta propuesta la posibilidad de formar parte del Área de la Universidad que promueve la transferencia de conocimientos a la comunidad, y, el interés personal por provenir de una familia minera.

Por último, el paradigma ético-político que asumo como trabajadora social, postula que toda población etaria debe ceñirse en la libertad, ciudadanía y justicia social. Todo ello en pos de la búsqueda de una sociedad más justa, equitativa y de integración. Es elemental que como ciudadanos estemos creando espacios de socialización que den prueba del sentido de construcción analítica de nuestra historia como cuenca carbonífera, escenarios que doten de sentidos a las vivencias y anécdotas que contienen los mineros antiguos que forman parte de la tercera edad, siendo ellos fundamentales en la construcción histórica de la cuenca.

\section{Metodología de trabajo}

El trabajo interinstitucional e interdisciplinario fortifica el lazo social y participación mancomunada entre la comunidad y universidad, el trabajo comunitario cargado de cientificidad conlleva a un compromiso ciudadano y político en donde la población universitaria se vincula además con el gobierno local. Logrando así desarrollar la investigación y la extensión desde un enfoque de derechos, en pos de garantizar la participación, ampliar los conocimientos y propulsar la interdisciplinariedad en función de las necesidades colectivas, culturales, sociales, ambientales y tecnológicas.

En término de recursos humanos, la interrelación de la comunidad universitaria con la comunidad tiene la intención de la conformación de equipos técnicos cada vez más sensibles a las necesidades de la población. Esto postula que no existe un adentro y un afuera, afirmamos que asumir el tratamiento de temas regionales desde el ámbito académico, apuntalan a garantizar la injerencia de acciones de desarrollo y cooperación que tendrán un impacto local y social. Además, desde el proyecto de extensión también vinculamos organizaciones no gubernamentales, asociaciones sociales, gremios $u$ sindicatos y centros de jubilados, con el fin de ampliar los espacios de interacción y de escucha.

Creemos indispensable una gestión responsable por parte del sistema universitario y gobierno local, porque el compromiso real de las partes coloca en agenda la importancia de hacer visible los bienes culturales, logrando el involucramiento de la sociedad en su conjunto. Identificamos como punto de partida el reconocimiento de un elemento significativo como lo es la historia oral de los mineros antiguos hoy jubilados acerca de los inicios de la explotación del carbón, los cuales acontecieron hechos trascendentales como las luchas por la defensa de la mina, $y$, un hito trascendental como lo fue el siniestro en interior de mina ocurrido en junio del año 2004. 
Ciertamente las trayectorias laborales del minero en un contexto determinado, vinculado a la dimensión económica, social, cultural, e ideológica enmarcan un tipo de sujeto en el territorio que allega. Retomando la voz del antiguo minero, el discurso oral como bien cultural se enfatiza en su inserción a la villa minera, el trabajo que dignifica, las necesidades que aparejaban los trabajadores, el proyecto de vida, la trascendencia de estabilidad laboral y la representación social de ser minero como superación.

El método a utilizar es el dialectico, porque de esta manera el intercambio oral será reciproco y horizontal. Por tal motivo, en los espacios de talleres u jornadas, el educador/moderador debe interactuar con actitud dialógica para que los participantes aporten sus puntos de vista, historias de vida, anécdotas y reflexiones acerca de sus representaciones sobre el trabajo, la mina, el yacimiento carbonífero y demás clivajes culturales. Generando de esta manera la escucha de las significaciones que se den en el espacio, ya que el contenido se construirá entre ambas partes.

Desde la perspectiva crítica sostenemos que la acción educativa consiste en escuchar desde un margen de criticidad y libertad, reflexionando acerca del lugar que ocupa el sujeto en el mundo, y el porqué de los procesos sociales a partir del conocimiento de la coyuntura. La organización es participativa porque los participantes son sujetos de conocimientos que expresaran en las actividades y en los talleres sus representaciones sociales sobre el minero. El eje de la participación estará concentrado en el crecimiento en conjunto de todos los sujetos, donde se plasmará la idea de interacción grupal, y como esta acción genera cambios generales en el equipo.

Institución involucrada: La seccional ATE jubilados (argentinos y chilenos) comprende que es necesario la vinculación con la Universidad para acciones superadoras desde la extensión, que conglomere a estudiantes y el plantel docente sensibilizados a lo que implica la historia, cultura e identidad minera. Ciertamente desde el planteamiento del objetivo del proyecto, la seccional de jubilados coincide en la visión de concluir el trabajo con el armado de un libro que relate la trayectoria laboral del minero y la historia del yacimiento carbonífero desde un aspecto antropológico y social.

También la seccional se compromete a cooperar en el plano técnico, espacial y extensivo en cuanto a la realización de las acciones dinámicas y recreativas de alumnos de la Licenciatura en Trabajo social y demás carreras que se asocian bajo la coordinación del presente programa de extensión.

\section{Actividades proyectadas en el término de un año}

META 1: Primera antología denominada "Mi papá minero"

Espacio socio educativo- actividad literaria: Confección de relatos anecdóticos por los hijos de mineros jubilados del YCRT

Participación de los hijos de mineros antiguos (referencia a los trabajadores jubilados posterior al año 2004) en la actividad literaria denominada "Mi papá minero". La cual consiste en relatar de manera anecdótica las vivencias e imágenes representativas 
que retrae en sus vivencias y recuerdos en cuanto al trabajo minero de su padre y la mina como espacio laboral de conformación de identidad.

a) Convocatoria de participación a los hijos de mineros jubilados para la presentación de los relatos anecdóticos. Socialización de las bases de presentación de la actividad literaria.

b) Envío de los relatos a un correo electrónico.

c) Edición de los relatos por parte del equipo.

d) Exposición y promulgación de la primera antología denominada "Mi papá minero". Se proyecta sea por medio de recursos digitales y en formato impreso.

META 2: Apartado anexo de la antología; Los apodos funcionales en mineros antiguos del YCRT.

Espacio socio educativo- actividad literaria y radial: Confección de relatos que enuncien los apodos del minero y el porqué de la denominación, lo cual se caracterizan en su mayoría por la funcionalidad u oficio dentro de interior de mina.

Participación por parte de la comunidad, familiares y amigos de los mineros de la cuenca carbonífera.

META 3: Exposición de fotografías y dibujos denominado "la imagen como espejo de recuerdos"

Participación de artistas e integrantes de la comunidad de la cuenca carbonífera para que participen por medio de una imagen representativa y simbólica respecto a dos eventos trascendentales en la mina, que marcaron un antes y un después para el minero y los pueblos caracterizados por la extracción minera; -La lucha en defensa de la mina del año 1994 a los fines de que la empresa siga en funcionamiento. Y, -El siniestro trágico de los 14 mineros como evento que genero cambios en el aspecto laboral y derechos que se luchaban.

a) Convocatoria de participación a la comunidad en general para la presentación de dibujos y fotografías. Socialización de las bases de presentación de la actividad de expresión.

b) Envío de las imágenes por correo electrónico.

c) Edición de las imágenes por parte del equipo, para a posterior ser promulgados a la comunidad por medio de recursos digitales.

d) Exposición de las imágenes por medio de las paginas digitales.

META 4: Jornada reflexión mediado por las herramientas tecnológicas; "Ser el engranaje de las máquinas" recordando los records en producción

Participación de los mineros jubilados en un espacio previamente planificado para la generación de dialogo fluido, de carácter reflexivo, de posturas críticas y de resignificación identitaria en cuanto a la subjetividad que tiene con el trabajo en interior de mina, su participación en eventos de lucha, y su apreciación e implicancia en ser minero. 
Se trabajará con entrevistas grabadas, respecto a la construcción de relatos biográficos e historias de vida del minero para dar cuenta de la significación de ciertos lugares, artefactos y relatos específicos de eventos trascendentales en la mina.

Estos insumos previamente establecidos y organizados, conllevarán a un espacio en vivo mediado por la virtualidad que será de carácter abierto a la comunidad. Se proyecta una jornada de dos días con la puesta en común de las grabaciones divididos por lapsos de conversatorios que serán moderados por colaboradores. Al cual le corresponde un papel protagónico desde un aspecto de ampliación, desarrollo y participación integral de los sujetos, este tendrá una interacción dinámica y dialógica fortaleciendo la participación de los usuarios en su totalidad.

Entendemos que la memoria debe ser preservada en el tiempo, significados que los mineros le atribuyeron a su condición de laboreo, y fueron condicionados por el contexto e historia que atraviesa.

a) Armado de actividad; planificación, invitación a panelistas que tendrán la función de moderador, preparación de los que tendrán el rol de grabar los relatos, cuestiones técnicas del recurso audiovisual a utilizar.

b) Jornada "Ser el engranaje de las máquinas"

c) Armado de una producción literaria con los hallazgos e insumos rescatados.

\section{Recursos Humanos}

- $\quad$ Plantel Docente y estudiantes de las carreras de la Licenciatura en Trabajo Social.

\section{Recursos de Infraestructura}

- Espacio audiovisual

- Herramientas digitales

\section{Estrategia de sostenibilidad a futuro}

Desde el planteamiento de los objetivos del proyecto a diversas entidades como ATE que nuclean a mineros del YCRT, se ha logrado congeniar con ellos un sentido de cooperación y colaboración en las acciones y actividades que pretenden resignificar las historias de vida, trayectorias laborales y anécdotas de los jubilados mineros. Básicamente el armado de un libro ha conquistado espacios tanto institucionales y familiares.

El trabajo de poner en valor la historia oral de minero en la cuenca carbonífera es un área de vacancia hoy en día. Consideramos que en el transcurso del proyecto y con la demostración de los eventos novedosos de expresión que trastocan la identidad de pueblo minero, se sumaran a cooperar otras entidades e individuos sensibilizados. 
En ese punto, creemos fundamental desde nuestro lugar como académicos y extensionistas accionar en lógicas arribadas al resguardo y gestión del patrimonio de bienes inmateriales como el relato oral, los mitos, las tradiciones. La conservación de los bienes culturales que con el tiempo se deterioran u se desvanecen obtiene relevancia para los pueblos caracterizados por la extracción minera, efectuar la resignificación de la memoria desde un trabajo participativo integral permite hacer compartida la identidad, se generaliza una razón de ser para un pueblo y su cultura, vinculando el pasado con el presente y el quiénes somos como comunidad.

Los objetivos del trabajo se materializarán bajo el encuadre de la extensión universitaria, generando espacios, encuentros y actividades que permitan por medio del discurso y relato oral de los mineros y comunidad; la construcción simbólica e histórica del Yacimiento Carbonífero Rio Turbio. El insumo como hallazgos teóricos permitirá dar cuenta de los elementos u bienes culturales que identifican colectivamente los sujetos. Si bien actualmente la cuenca carbonífera se halla atravesada hoy en día por una etapa de transición en cuanto a las políticas extractivas y estabilidad laboral, consideramos oportuno acentuar más firmemente el trabajo planteado, asentimos que la vivencia colectiva en momentos críticos produce mayor unificación y participación social.

\section{Resultados esperados}

- $\quad$ Promover instancias de encuentros reflexivos que incentive al conocimiento crítico e indagación de las trayectorias laborales del minero.

- Impulsar en los jubilados mineros al arte de la comunicación desde las TIC como sinónimo de expresión y herramienta de relevancia para el cambio social e cultural.

- Trabajo socio-comunitario.

- Desarrollo integral local.

- Población comunitaria sensibilizada en cuanto a la valoración de bienes inmateriales, como lo es la historia oral del minero.

\section{Referencias bibliográficas}

BOURDIEU, P. (1990) (1978). "La juventud no es más que una palabra” en Bourdieu, P. Sociología y cultura. México: Grijalbo.

CHAVES, M. (2005). "Juventud negada y negativizada: representaciones y formaciones discursivas vigentes en la Argentina contemporánea". Revista última década Año 13 N 23 Viña del Mar. https://doi.org/10.4067/S0718-22362005000200002 
CISELLI, G. (2018). El acceso a la participación como mecanismo de preservación del patrimonio cultural ante los gobiernos locales en Revista Textos y Contextos desde el $\begin{array}{llllll}\text { Sur } & \text { No } & 6 . & \text { UNPSJB. } & \text { Pp. } & \text { 133-152. }\end{array}$ http://www.revistas.unp.edu.ar/index.php/textosycontextos/article/view/12

DAVALLON, J. (2014). "El juego de la patrimonialización", en Construyendo el patrimonio cultural y natural. Valencia, Ed. Germania, pp. 47: 76.

DÍAZ, E.; HELER, M. (1988) "El conocimiento científico". El discurso. Ed. Universitario de Bs.As. Volumen 1 y 2.

DUARTE CASTELLANO, D. (2012). Investigación Las minas de carbón berciana. Tutor: Francisco Javier Soriano Martín Graduado Universitario Senior -3--Universidad Jaume I-Curso 2012-

GODOY, C. J. (2000). El Gran Libro de la Provincia de Santa Cruz. Tomo 2. Sección Rio Turbio Pág. 670. Milenio Ediciones.

GOFMANN, E. (1972). Internados. Editores Amorrortu. Buenos Aires Argentina.

HERNÁNDEZ ZAMORA, G. (1992). Ensayo sobre identidad e identificación. Marzo 1992.

JARA, A.; ILLANES, N.; HERMANN, I. (2009). Un pueblo que vive y late. Editados el volumen 1 en 2007 y el volumen 2 en 2009. Rio Turbio. Santa Cruz.

LABARTHE, G. (2014). "Globalización, ajuste y carbonen la cuenca carbonífera de Rio Turbio" Edición UNPAedita.

MANNHEIM, K. (1993). El problema de las generaciones. Ed. Reis. Pp 193-242. https://doi.org/10.2307/40183643

MARGULIS, M.; URRESTI, M. (1996). La juventud es más que una palabra. Ensayos sobre cultura y juventud (Cap 1). Buenos Aires: Editorial Biblos.

MARGULIS, M.; URRESTI, M. (1998 a). La construcción social de la condición de juventud. En H. Cubides; M. Laverde y C. Balderrama (Ed.). Viviendo a Toda. Jóvenes, territorios culturales y nuevas sensibilidades, (pp 3-21). Bogotá: Siglo del Hombre.

MARGULIS, M.; URRESTI, M. (1998b). "La construcción social de condición de juventud" en Cubides, H, Laverde, M.C. y Valderrama C. (EDS) (Criado 2005 "se es viejo y joven para algo".

RODRÍGUEZ-CARMONA, A. (2013). Imaginarios a cielo abierto. Una mirada alternativa a los conflictos mineros en Perú y Bolivia. Acsur las Segovias.

SVAMPA, M. (2000). De la patria metalúrgica al Heavy metal. Artículo publicado en el libro Desde Abajo. Buenos Aires. Biblos.

TAUSSIG, M. (1993). El Diablo y el fetichismo de la mercancía en Sudamérica. Nueva Imagen.

ZAIAT, A. (2004). El espejo de la mina. Página 12. Martes, 22 de junio de 2004.

ZAPATA, F. (2002). Los mineros como actores sociales y políticos en Bolivia, Chile y Perú durante el siglo XX. Centro de Estudios Sociológicos, El Colegio de México, Camino al Ajusco 20, Apto Postal 20-671, 01000 México D. F. https://doi.org/10.4067/S0718$\underline{10432002002200006}$ 
ZOCCOLA, E. P. (1973). Rio Turbio; Gesta del carbón argentino. Buenos Aires. Editorial YCF (Yacimientos carboníferos fiscales).

* Gisel Elvira Barboza: Docente extensionista e Investigadora, y Directora Normalizadora de la Escuela de Trabajo Social de la UART-UNPA. Pcia. De Santa Cruz. Argentina. [E-mail: gevy1987@hotmail.com ] 